\title{
Adapting Education at the Medical College of Georgia at Augusta University in Response to the COVID-19 Pandemic: the Pandemic Medicine Elective
}

\author{
Joseph Antony Elengickal ${ }^{1}$ (1) Amanda M. Delgado ${ }^{1} \cdot$ Shefali Priya Jain $^{1} \cdot$ Elena Rae Diller ${ }^{1} \cdot$ Catherine E. Valli $^{1}$. \\ Kesar K. Dhillon ${ }^{1} \cdot$ Hee K. Lee ${ }^{1} \cdot$ Rohitha Baskar $^{1} \cdot$ Rodger D. MacArthur $^{2}$
}

Accepted: 14 January 2021 / Published online: 27 January 2021

(C) International Association of Medical Science Educators 2021

\begin{abstract}
The Medical College of Georgia (MCG) responded to the COVID-19 pandemic's challenges to medical education with a novel, comprehensive curriculum. The Pandemic Medicine Elective was an effective solution with a safe, virtual alternative to traditional clinical experiences. As the elective evolved to include pre-clinical students and service initiatives across Georgia, students and faculty navigated online platforms to execute critical community-based projects. This curricular development utilized an interdisciplinary approach by faculty across each of MCG's regional campuses. We describe the curriculum of the electives, the student initiatives, and lessons learned while quickly adapting curriculum during the COVID-19 pandemic.
\end{abstract}

Keywords Medical education $\cdot$ Medical student $\cdot$ COVID-19 $\cdot$ Distance learning $\cdot$ Service learning $\cdot$ Community engagement

\section{Background}

As of December 15, 2020, there were over 73.4 million confirmed cases worldwide of the novel severe acute respiratory syndrome coronavirus 2 (SARS-CoV-2) [1]. While the COVID-19 pandemic disrupted many aspects of daily life, one of the most significant consequences of the virus was school closures, affecting over 1 billion learners in 111 countries [2]. The Centers for Disease Control and Prevention emphasized school closure as an essential social distancing strategy [3]. From elementary schools to universities, educational institutions faced unprecedented challenges stemming from an extended period of interrupted learning [4]. Medical colleges have particularly struggled to make virtual the hands-on educational and clinical experiences necessary for becoming a physician [5]. To ensure and prioritize the safety of students, many medical schools transitioned their pre-clinical students

Joseph Antony Elengickal

jelengickal@augusta.edu

1 Office of Academic Affairs, Medical College of Georgia at Augusta University, Augusta, GA, USA

2 Department of Medicine, Division of Infectious Diseases, Medical College of Georgia at Augusta University, Augusta, GA, USA to online instruction, proctored online-examinations, and paused in-person rotations.

Medical schools also quickly adapted their clerkship programs to ensure students received meaningful curricular experiences throughout the pandemic. As the Association of American Medical Colleges (AAMC) stressed the importance of delivering remote care in response to the pandemic, medical schools chose to feature telemedicine in their adapted curriculums [6]. In response to the pandemic, AAMC telehealth competencies served as the cornerstone for many curricular experiences delivered to third- and fourth-year medical students across the nation [7]. For example, the Larner School of Medicine implemented an elective following the guidance of a module developed by the American College of Physicians in order to further understand the key aspects of telemedicine $[8,9]$. At the University of Minnesota, students engaged with a curriculum to implement their new telemedicine skills. Students organized patient placement and transfers, all from the safety of their remote Systems Operation Center [8, 10]. At the same time, students at the Boonshoft School of Medicine participated in online modules focused on psychological first aid. Following the course, students utilized their telemedicine skills during scheduled social visits with elderly members in the local community $[8,11]$.

While medical schools across the USA used new curricula to merge student education with service in the wake of the 
pandemic, none was able to establish a program with a profound, statewide impact like the one started at the Medical College of Georgia (MCG). In response to the unconventional pause in hands-on learning and clinical rotations, MCG developed a novel solution, delivering lectures and facilitating community service in the form of a virtual Pandemic Medicine Elective. This elective was unique in that it provided students with breaking coverage of the novel SARS-CoV-2 through an interdisciplinary approach. Discussions with regard to medical ethics, health systems, and global health supplemented lecture content and motivated students to develop service projects that would unite MCG's statewide campuses. This paper is an expository work that details the creation of the elective, followed by its impact on the community and subsequent lessons it taught the faculty and students at MCG.

\section{Initial Response to the Pandemic}

On March 12, 2020, the University System of Georgia (USG) announced a two-week suspension of educational instruction. At MCG, faculty shifted the first- and second-year curriculum to an online platform. Lectures were replaced with recorded materials from previous years, while other in-person activities such as small group case-based sessions, clinical skills training, anatomy lab, and testing were either temporarily suspended or transitioned online. On March 17, 2020, the AAMC and LCME released a statement urging a "pause" in patient contact for third- and fourth-year medical students, leading MCG to officially remove students from their clinical rotations on March 18, 2020. As the pandemic worsened and students were urged to shelter-in-place, these modifications to pre-clinical and clinical learning were extended for the remainder of the semester.

Steps to ensure an enriching alternative to clinical education required thorough consideration. The administration at MCG turned to a pre-existing summer program, Areas of Concentration, for inspiration. Traditionally offered to rising second-year students, the Areas of Concentration program was delivered in previous years as a four-week elective with different medically related topics that students could choose from: Ethics, Leadership, Global Health, Public Health, Health Policy, and Artificial Intelligence and Machine Learning. Each Area of Concentration has historically been facilitated by a faculty member with extensive knowledge in the specific field. In response to the COVID-19 pandemic, the professors involved in each concentration contributed their expertise to create a new elective: The Pandemic Medicine Elective.

The initial goal of the Pandemic Medicine Elective was to provide third- and fourth-year medical students with a curricular offering in lieu of hospital activities. The elective would take place in a safe, virtual setting as the extent of the virus continued to evolve. Microsoft Teams was the online platform-of-choice for its dual ability to deliver live lecture content and offer small sub-channel "teams" for students to engage in group work. Beyond the virtual classroom, the elective also offered students an opportunity to address public health challenges through service initiatives across the state. The initial version of the elective covered COVID-19 topics including basic science, healthcare systems, and health professionals. After the first iteration of the elective, student survey responses were considered to tailor the Pandemic Medicine Elective 2.0 towards rising second-year medical students. A third iteration, the Pandemic Medicine Selective, was offered to rising third-year students who were delayed in entering clinical rotations due to complications at rotation sites. Figure 1 outlines the timeline for the electives and selective, as well as other important events related to the pandemic for perspective. Details on the topics covered, organization of the courses, and student impacts are elaborated throughout this paper.

\section{MCG Initiatives}

\section{Pandemic Medicine Elective 1.0}

The first iteration of the elective was structured into four weeks of instruction: two hours of lectures four days a week, and one day dedicated to experiential learning and service. Table 1 lists lecture topics covered over the four weeks.

Faculty previously involved in MCG's previous Areas of Concentration Program presented lectures based on their interests and experience. A team of physicians and educators from the Departments of Family Medicine, Cardiology, Surgery, Pediatrics, Infectious Diseases, and Emergency Medicine were involved in constructing the elective and daily lectures. Non-clinical departments at Augusta University including the Department of Population Health Sciences, the Division of Epidemiology, the Institute of Public and Preventative Health, and the Center for Bioethics and Health Policy also contributed to lecture content. Along with the Georgia Prevention Institute, these organizations provided a robust background that conveyed the basic science with regard to SARS-CoV-2 and the challenges it created for healthcare and the public sector. Guest lecturers from other institutions including Georgia State University and the Dental College of Georgia were invited and interviewed for the special discussion topics, such as "Military medicine," "Delivering healthcare in a crisis," and "Professional and personal responsibility." Additionally, students in the elective were offered the opportunity to submit lecture proposals. Students' presentations focused on topics including health policy and corona virus, communication during a crisis, and vulnerable populations. Students also participated in small 


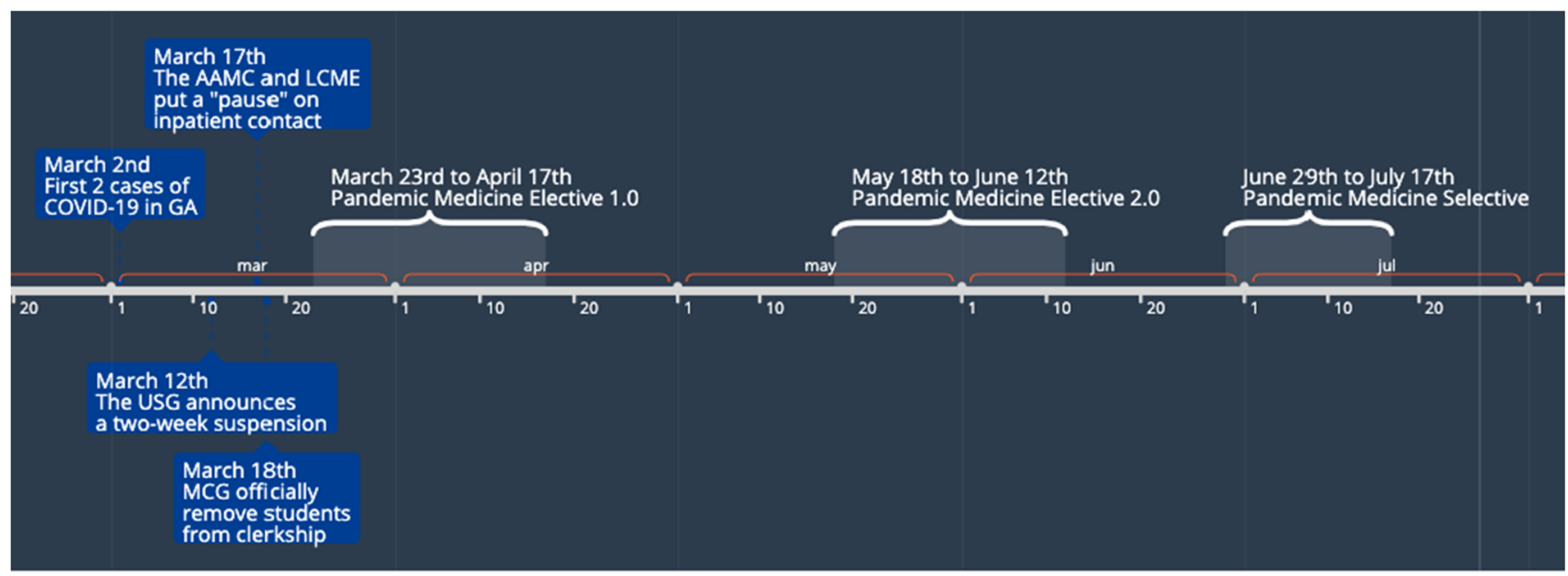

Fig. 1 Pandemic and MCG response timeline

group discussions following lectures, with faculty rotating between groups to offer guidance.

Student completion of the course was dependent on the following areas: attending class, writing a reflection paper, and participating in 8 service-learning hours. The prompt for the two-page reflection paper encouraged students to share their experiences during the course and describe the impact the elective had on their perspective as future physicians. To complete the service-learning requirement, students joined a student-led, community-based initiative which focused on current public health challenges. These initiatives are further discussed in the "Student Initiatives" portion below. In order to assess student attitudes towards the course, weekly surveys were conducted to evaluate student opinions on the previous weeks' lectures. A total of 186 students participated in this pass-fail course that counted towards elective credit. The course ran from March 23 until April 17.

\section{Pandemic Medicine 2.0 (PanMed 2.0)}

A second version of the Pandemic Medicine Elective was offered to rising second-year medical students, as well as a limited number of dental students, PhD students, and oral and maxillofacial surgery residents. With summer research programs canceled, students were eager to engage with faculty
Table 1 Pandemic Medicine Elective 1.0 curriculum

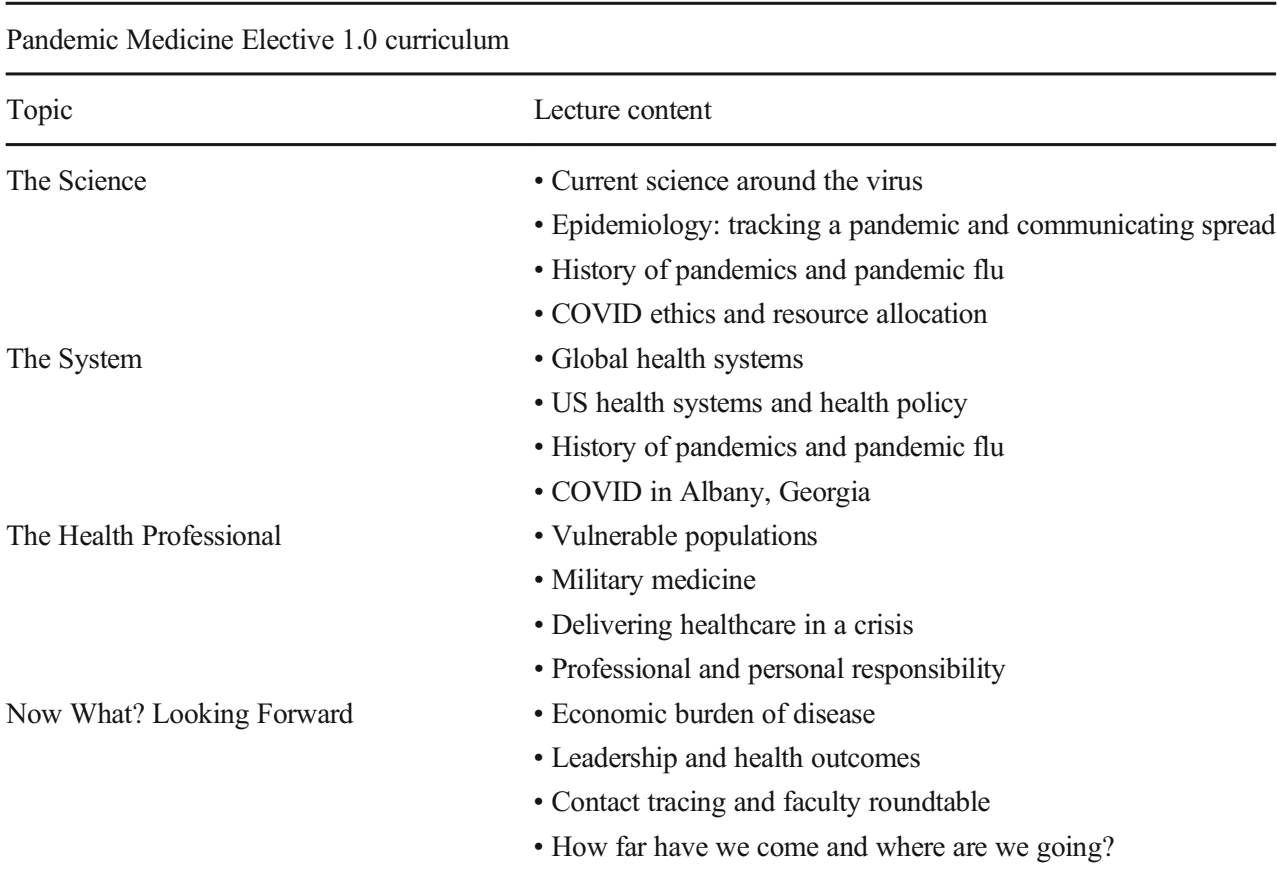


and content experts on relevant health topics. PanMed 2.0 emphasized clinical perspectives with the intent to engage those in the audience with minimal clinical experience. Table 2 lists the lectures given over the four-week course.

The lectures predominantly covered the basic science and research with regard to the virus, what different healthcare systems have done to combat the virus as well as the effect of the virus on these systems, the impact of the virus on individuals, and future developments to combat the virus. The students listened to interviews of physicians battling the pandemic in China as well as Germany. They participated in a live lecture and Q\&A session with a physician who compared her experience of working in Guinea during the Ebola crisis to that of COVID-19 in New York City. These viewpoints highlighted the international magnitude of the pandemic, as well as the grim reality healthcare providers around the world face during a health crisis.

The requirements for successfully completing PanMed 2.0 closely mirrored those established by the first version of the elective. Participants were required to write a final paper that addressed the challenges created by the pandemic and their impact on social well-being, economic stability, and the needs of health systems. Students also completed a total of at least 8 service-learning hours, serving across the state through the student-led initiatives established in the first iteration of the elective. A total of 85 students participated in this pass-fail course. The elective ran from May 18 until June 12.

\section{Pandemic Medicine Selective}

A third version of the course was offered to a select group of clinical students whose Neurology/Psychiatry rotations were delayed. The Pandemic Medicine Selective focused on preparing students for their new clinical environment during the COVID-19 pandemic. While the Pandemic Medicine Selective included topics from the previous iterations of the elective, it focused more heavily on the impact of the pandemic on providers and their delivery of care. Once again, an interdisciplinary team of educators and community leaders from across Georgia came together to deliver clinically relevant content. This team that delivered clinically relevant content throughout the selective included physicians across MCG's statewide campuses, faculty from MCG's Center for Bioethics and Health Policy, the medical examiner for Glynn County, the public health district director of Rome, GA, the medical director of a community health clinic in Athens, GA, the medical director of Georgia War Veteran's Nursing Home, hospital administrators from Phoebe Putney Memorial Hospital in Albany, GA, residents, medical students, critical care pharmacists, a COVID-19 research scientist, and even an
Table 2 Pandemic Medicine Elective 2.0 curriculum

\begin{tabular}{|c|c|}
\hline Topic & Lecture content \\
\hline The Science & $\begin{array}{l}\text { - The US healthcare system vs. global } \\
\text { - Epidemiology tracking of a pandemic } \\
\text { - Historical pandemic } \\
\text { - COVID-19 testing: starting from scratch } \\
\text { - Ethics }\end{array}$ \\
\hline The System & $\begin{array}{l}\text { - The US healthcare system vs. global health systems } \\
\text { - How the US system arrived here } \\
\text { - Individual health systems' response to COVID-19 } \\
\text { - Test strategies: case studies and test strategy debates }\end{array}$ \\
\hline The Individual & $\begin{array}{l}\text { - Vulnerable populations } \\
\text { - Pediatrics } \\
\text { - Delivering healthcare in a crisis } \\
\text { - Molecular basis of infectivity and transmission, the basics } \\
\text { of vaccine development, therapeutic approaches }\end{array}$ \\
\hline Where Do We Go from Here? & $\begin{array}{l}\text { - Changes in the healthcare landscape: moving to the } \\
\text { telemedicine platform } \\
\text { - Economic burden of illness } \\
\text { - COVID-19's system effects } \\
\text { - Pathophysiology } \\
\text { - Vaccines } \\
\text { - Practice implication and specialty choices }\end{array}$ \\
\hline
\end{tabular}


executive chef. The selective featured unique lecture topics such as proper donning and doffing of PPE, telemedicine simulations, disaster life support training, and required students to research a clinical topic related to COVID-19 and their medical specialty of interest. Table 3 lists all the lectures provided during the Pandemic Medicine Selective. The smaller class size of 10 students allowed for in-depth discussion between the students and teaching faculty. Students worked in groups to complete their service-learning requirement and continue the COVID-19 response initiatives from Pandemic Medicine 1.0. Each group delivered a 15-minute presentation featuring their projects by the end of the selective. This version was three weeks with lectures two hours a day, four days a week. The selective was a pass-fail course, running from June 29 until July 17.

\section{Student Initiatives}

All three iterations of the Pandemic Medicine Elective included a service component through student-led COVID-19 initiatives. These initiatives were developed and initially led by third- and fourth-year medical students and included Medical Education, Information Services, PPE, Tele-Medicine, and Mental Health and Well-Being.

The Medical Education Initiative initially focused on (1) delivering 5-minute "Daily COVID-19 Updates", which highlighted COVID-19 trends and featured news stories, and (2) contributing summaries of pre-print research papers to a database. In the second and third iterations of the elective/ selective, students began working on COVID-19 research projects with the guidance of faculty advisors. They continue to grow the "COVID-19 Updates" as weekly presentations on YouTube and work on other research projects.

The Information Services Initiative focused on creating high-quality, concise resources on the COVID-19 pandemic.
These resources were published on a website created by the students: www.mcgcovidresponse.com. The team developed a number of resources such as weekly literature reviews, myth busters, and infographics. They developed a daily blog with local COVID-19 news, created a designated page to list social services in the area, and responded to dozens of comments and questions about COVID-19 from the site visitors. Through robust social media efforts targeting local audiences, the website saw a total of 5500 unique views and over 10,000 page views in the three-week period of the selective. The team continues to maintain the website into the school year and work with local businesses and institutions to increase the website's presence and reach. They are also developing a partnership with a local elementary school to teach children about COVID-19.

The PPE Initiative organized teams that procured resources, manufactured PPE, and fundraised to protect frontline healthcare workers. The six subgroups within the initiative were (1) The Large/Local Business Outreach Group reached out to businesses for food and monetary donations. They also organized food delivery and care packages to frontline workers at the Augusta University Medical Center (AUMC). (2) The PPE Purchasing Group coordinated with authorized PPE manufacturers to distribute N95 masks, gloves, and face shields to frontline workers. (3) The PPE Donations Group sought donations from businesses and organized a system to collect unused masks and gloves from the anatomy lab at MCG. (4) The Fundraising Group raised $\$ 15,000$ through GoFundMe and other fundraising efforts. (5) The Handmade Mask Task Force acquired supplies, mobilized student volunteers across Georgia to sew and distribute over 3100 masks. (6) The Face Shields Group initiated efforts to 3D-print face shields and face drapes in the Augusta area. The team continues to recruit volunteers to
Table 3 Pandemic Medicine Selective curriculum

\begin{tabular}{ll}
\hline Pandemic Medicine Selective curriculum & \\
\hline Topic & Lecture content \\
\hline COVID-19 Overview & $\cdot$ The science of COVID-19 \\
& $\bullet$ COVID-19 in different clinical settings panel discussion \\
& $\cdot$ Supporting patient and families through COVID-19 \\
& $\cdot$ Provider wellness; patient's experience with COVID-19 \\
COVID-19 and the Healthcare System & $\bullet$ COVID-19 and healthcare \\
& $\cdot$ COVID-19 and learner preparation and experiences \\
Interactive Components & $\cdot$ Disaster basic life support course \\
& $\cdot$ Telemedicine simulation and PPE exercise \\
COVID-19 and Community & $\cdot$ COVID-19 and the community \\
& $\cdot$ COVID-19 and specialty care/research \\
& $\cdot$ Pandemic initiatives presentations
\end{tabular}


participate in the Handmade Mask and Face Shield subgroups and provide resources to communities in need.

The Tele-Medicine Initiative focused on promoting telemedicine efforts at Augusta University (AU) Health and across Georgia. During Pandemic Medicine 1.0, medical students assisted over 400 patients by scheduling their telemedicine psychiatry appointments and help navigate the telemedicine software. Additionally, the team staffed the AU Command Center and partnered with over 100 clinics across Georgia to establish telemedicine services. During PanMed 2.0, students worked with student-run clinics in Augusta to set up telemedicine visits, evaluated the efficacy of telemedicine, participated in contact tracing with the Georgia Department of Public Health, developed education materials on telemedicine, and created telemedicine training materials for incoming first-year medical students. The team is collaborating with physicians to create more telemedicine opportunities in the future.

The Mental Health and Well-Being Initiative worked to foster positive mental health and well-being within the MCG community and beyond. These efforts included (1) a biweekly wellness newsletter which provided ideas for wellness activities; (2) physical wellness activities such as a student-led, virtual yoga workout and a weeklong school-wide step count race; and (3) daily Instagram takeovers by students to share wellness tips. The team also collaborated with MCG's "Music in Medicine" organization to develop an initiative called "Songs of Comfort". The groups collected performances recorded by students and faculty to share them via social media. The goal of "Songs of Comfort" was to provide relief to frontline workers and their families during these isolating times.

\section{Regional Campus Initiatives}

As the only public medical school in Georgia, MCG has regional campuses across the state, including the Southeast campus based in Savannah, the Southwest campus based in Albany, and the Northwest campus based in Rome. The unique expansiveness of MCG's campuses gave students the ability fight COVID-19 statewide. By surveying where students were sheltering in place, MCG mobilized students to support the service initiatives where help was needed in the state.

The PPE Initiative mobilized students across the state to provide aid to the COVID-19 hotspot in Albany, GA. Students sewed masks, shipped PPE to Albany, raised money for families who had been affected by COVID-19, and made care packages for local physicians and patients in need.

Students on the Southeast campus initiated contact tracing efforts later supported by the Georgia Department of Public Health and the Tele-Medicine Initiative. Students also assisted with telemedicine support services, delivered groceries to vulnerable populations, and fundraised to assemble over 450 care packages for those in the healthcare community.

Table 4 Pandemic elective initiatives

\begin{tabular}{|c|c|c|}
\hline Initiative & Goal & Outcomes \\
\hline Medical Education & $\begin{array}{l}\text { Update the class with the latest information } \\
\text { related to the pandemic and review new } \\
\text { publications and pre-prints for easy access. }\end{array}$ & $\begin{array}{l}\text { 1. Presented } 44 \text { COVID update presentations to the class } \\
\text { 2. Summarized } 155 \text { publications and pre-prints related to } \\
\text { COVID-19, creating the MCG COVID Knowledge Bank }\end{array}$ \\
\hline Information Services & $\begin{array}{l}\text { Educate the MCG and greater Augusta } \\
\text { community about the COVID-19 pandemic } \\
\text { by creating high-quality, concise resources. }\end{array}$ & $\begin{array}{l}\text { 1. Developed a website to publish local COVID-19 news } \\
\text { and resources, which has generated over } 5500 \text { unique } \\
\text { views and over } 10,000 \text { page views } \\
\text { 2. Created over } 50 \text { myth busters and } 20 \text { infographics which } \\
\text { were translated in up to } 10 \text { languages }\end{array}$ \\
\hline PPE & $\begin{array}{l}\text { Organize efforts to increase the amount of } \\
\text { PPE available to frontline workers } \\
\text { across the state of Georgia. }\end{array}$ & $\begin{array}{l}\text { 1. Purchased and delivered } 500 \text { NP5 masks, } 3000 \text { pairs of } \\
\text { gloves, and } 300 \text { face shields to frontline workers } \\
\text { 2. Coordinated fundraising efforts to raise } \$ 15,000 \text { for PPE } \\
\text { 3. Made over } 3100 \text { face masks and shields for frontline workers }\end{array}$ \\
\hline Tele-Medicine & $\begin{array}{l}\text { Promote telemedicine efforts across the } \\
\text { state of Georgia. }\end{array}$ & $\begin{array}{l}\text { 1. Scheduled over } 400 \text { psychiatry appointments via telemedicine } \\
\text { 2. Develop educational materials about telemedicine }\end{array}$ \\
\hline Mental Health and Well-Being & $\begin{array}{l}\text { Foster mental health and well-being } \\
\text { within the MCG community and beyond. }\end{array}$ & $\begin{array}{l}\text { 1. Shared wellness tips through a newsletter and social media } \\
\text { 2. Facilitated virtual physical-wellness activities } \\
\text { 3. Collaborated with musicians to provide comfort to frontline workers }\end{array}$ \\
\hline Regional Campus Initiatives & $\begin{array}{l}\text { Implement COVID-19 relief initiatives } \\
\text { across Georgia using the infrastructure } \\
\text { of the MCG regional campuses. }\end{array}$ & $\begin{array}{l}\text { 1. Mobilized students across Georgia to create and ship } \\
\text { PPE to Albany (SW Campus) } \\
\text { 2. Initiated contact tracing efforts in collaborate with the } \\
\text { Georgia Department of Public Health (SE campus) } \\
\text { 3. Manned the phone centers in Rome to provide } \\
\text { COVID-19 support (NW campus) }\end{array}$ \\
\hline
\end{tabular}


On the Northwest campus, students worked with the District Health Director to manage the phone centers and provide COVID-19-related support, assist with contact tracing, and recruit individuals for a COVID-19 convalescent plasma study. The Northwest Campus students also worked on initiatives to deliver up-to-date informational videos in multiple languages.

The results of these student initiatives are summarized in Table 4. Upon completion of the Pandemic Medicine Selective, a total of 6198 hours had been logged related to the COVID student initiatives, with 4930 in the first elective, 1197 in the second elective, and 72 in the selective. Many students far surpassed the elective's 8-hour community service requirement and continue to serve as they extend their initiatives past the electives.

\section{Student Evaluations of Pandemic Medicine Electives/Selective}

Across all three versions of the elective, informal surveys were distributed to participating students. These surveys assessed student responses to lecture content, class format, and servicelearning opportunities. The following list includes the most popular lectures from the first iteration of the elective, with the percentage of students who rated the lecture very good or excellent using a five-level Likert scale: Epidemiology: Tracking a Pandemic and Communicating Spread (82.9\%), History of Pandemics and Pandemic Flu (79.9\%), and the Clinical Care at the Provider Level: Lessons from the Field (84.7\%). Moreover, these students positively responded to content related to ethics during a pandemic: COVID Ethics and Resource Allocation (79.7\%) as well as Professional Responsibility and Ethical Challenges (73.9\%). Students elaborated on their appreciation for the overall speed and quality of the elective in open-text comments. Moreover, they praised specific lectures including the History of Pandemics and Pandemic Flu. According to one student, "The faculty were very receptive to student feedback and did a very impressive job for this being a new course with a new platform."

When asked what aspect of the elective was most useful, students commented overwhelmingly on the variety of lecture topics and presenters. One student wrote, "The variety of perspectives...was special. Listening to nurses, physicians, admins all over the country talk about COVID-19 was a really enriching experience. My favorite class outside of a rotation taken." Students voiced gratitude for the elective as "a reliable source of information among the misinformation spreading during the pandemic," Another student echoed similar sentiments, sharing: "The elective helped to ground me and showed me that I can still help a lot during these uncertain times." Students felt empowered by the education and the elective's potential benefit to students' mental health cannot be underestimated and warrants further investigation.

\section{Lessons Learned}

The pandemic elective was quickly created in the span of two weeks to offer an option for third-year students to continue their education and fourth-year students to complete graduation requirements. This was possible due in part to the educational opportunities previously established, specifically the Areas of Concentration program. Utilizing the Areas of Concentration program's pre-existing infrastructure and the faculty's expertise was instrumental in designing a curriculum so rapidly.

Additional funding was not acquired for the curricular portion of the class. Participating faculty had strong intrinsic interest in seeing the electives/selective thrive at the start of the pandemic; therefore, students who chose to enroll were not charged additional tuition and faculty who delivered the content were not compensated additionally. The initiatives facilitated by the electives/selective were monetarily supported by fundraising efforts conducted by participating students. These students set up a GoFundMe page which collectively raised over $\$ 15,000$ for student-led initiatives.

As the only public medical school in Georgia, students share MCG's mission to serve the state. In this time of crisis, medical students and faculty collaborated to develop meaningful service initiatives. Students in leadership roles proved enthusiastic and innovative in methods to deliver PPE and create educational materials for the public. The passion students had for community service during the pandemic is exemplified through the unprecedented amount of volunteer hours, the numerous achievements of each initiative, and the drive to continue projects into the fall semester.

While the elective offered an alternative to rotations for students, it did not replace the experiences students would have gained in clinic. Lectures were informative and relevant but not equivalent substitutes to the hands-on skills medical students learn during their clinical rotations. Based on feedback from student surveys, students wished to learn more practical skills that may assist them in future public health challenges. For example, additional lectures on disease mapping and modeling via biostatistics, or using AI to address health and economic consequences due to the pandemic could provide practical instruction for those interested in assessing the pandemic's impact on public health. By adding these components and continuing to integrate more clinical topics, the Pandemic Medicine Elective could be offered in the future as a more practical course.

Additionally, while informal surveys were collected from students, formal evaluations of the lecturers and the lecture content were not completed. This was due in part to the limited time to prepare the electives. Formal evaluations would have been valuable in improving the electives especially in the subsequent PanMed2.0, Pandemic Medicine Selective, and any reiterations of the course that may follow in the future. 


\section{Conclusion}

The COVID-19 pandemic has substantially affected medical education. Faculty at MCG focused on providing students who were forced to leave their clinical assignments with an engaging curricular experience. The resulting pandemic-based curriculum filled the need for a virtual learning experience relevant to all phases of medical education. By adapting established curriculum and involving faculty from the Areas of Concentrations program, MCG was able to establish the Pandemic Medicine Elective 1.0 within two weeks of halting clinical rotations. The curriculum consisted of basic science lectures, healthcare policy discussions, and first-hand experience recollections from workers on the frontlines. From this blossomed a Pandemic Medicine 2.0 Elective, which served as a curricular experience for many rising second-year students who were displaced from their original summer plans. The evolving mission of the pandemic curriculum changed once more in the late weeks of the summer, as it provided third-year students experiencing delays in their clerkships with a curricular outlet in the form of a Pandemic Medicine Selective. Notably, students and faculty collaborated in establishing service initiatives that allowed students to volunteer in communities statewide. Students assumed leadership positions and, with regional campus representatives, expanded the reach of the school's impact during the pandemic. Through the pandemic, MCG proved resilient and adaptive in continuing education and serving the people across the state of Georgia.

Acknowledgments We thank the following individuals for their assistance in describing the pandemic electives: Dr. Douglas Miller, Dr. Kathryn Martin, Dr. Daniel Kaminstein, Dr. Douglas Patten, Dr. Daniel Rahn, Dr. Kimberly Loomer, Dr. Anna Edmondson, Dr. Jennifer Tucker, John Klement, and Shruti Gupta.

Data Availability Not applicable

\section{Compliance with Ethical Standards}

Conflict of Interest The authors declare that they have no conflict of interest.

Ethical Approval Not applicable

Informed Consent Not applicable
Code Availability Not applicable.

\section{References}

1. Johns Hopkins University of Medicine, Coronavirus Resource Center. COVID-19 dashboard by the Center for Systems Science and Engineering (CSSE) at Johns Hopkins University (JHU). 2020. https://coronavirus.jhu.edu/map.html. Accessed 31 Jul 2020.

2. United Nations Educational, Scientific, and Cultural Organization. Education: from disruption to recovery. 2020. https://en.unesco. org/covid19/educationresponse. Accessed 20 Jul 2020.

3. Center for Disease Control and Prevention. Operating schools during COVID-19. 2020. https://www.cdc.gov/coronavirus/2019ncov/community/schools-childcare/schools.html. Accessed 20 Jul 2020.

4. United Nations Educational, Scientific, and Cultural Organization. Adverse consequences of school closures. 2020. https://en.unesco. org/covid19/educationresponse/consequences. Accessed 20 Jul 2020.

5. Rose S. Medical student education in the time of COVID- 19 . JAMA. 2020;323:2131-2. https://doi.org/10.1001/jama.2020. 5227.

6. Redford G. Association of American Medical Schools. Delivering more care remotely will be critical as COVID-19 races through communities. 2020. https://www.aamc.org/news-insights/ delivering-more-care-remotely-will-be-critical-covid-19-racesthrough-communities. Accessed 31 Jul 2020.

7. Alliance for Academic Internal Medicine. AAIM connection April 16, 2020. 2020. https://www.im.org/blogs/aaim-administrator/ 2020/04/23/aaim-connection-april-16-2020. Accessed 31 Jul 2020.

8. Ferrel MN, Ryan JJ. The impact of COVID-19 on medical education. Cureus. 2020. https://doi.org/10.7759/cureus. 7492.

9. American College of Physicians. Telemedicine: a practical guide for incorporation into your practice. 2020. https://www.acponline. org/cme-moc/online-learning-center/telemedicine-a-practicalguide-for-incorporation-into-your-practice. Accessed 31 Jul 2020.

10. Atkins, K. University of Minnesota. New curriculum equips $U$ of $M$ medical students to support COVID-19 efforts. 2020. https://med. umn.edu/news-events/new-curriculum-equips-u-m-medicalstudents-support-covid-19-efforts. .

11. Kelly D. Wright State University. Department of Psychiatry responds to pandemic with virtual efforts 2020. https://webapp2. wright.edu/web1/newsroom/2020/05/12/department-ofpsychiatry-responds-to-pandemic-with-virtual-efforts/. Accessed 31 Jul 2020.

Publisher's Note Springer Nature remains neutral with regard to jurisdictional claims in published maps and institutional affiliations. 